\title{
Ideología revolucionaria y sociabilidad política en los grupos universitarios maoístas de los años 60 y 70 en Colombia*
}

\begin{abstract}
Álvaro Acevedo Tarazona
Profesor titular de la Universidad Industrial de Santander (Colombia). Correo electrónico: tarazona20@ gmail.com. El autor es doctor en Historia de la Universidad de Huelva (España). Miembro de la Asociación Colombiana de Historiadores. Entre sus publicaciones recientes tenemos: "Disputa electoral durante El Frente Nacional: las caricaturas de Chapete sobre Rojas Pinilla y la Anapo", en Revista Historelo Vol. 7 No. 13 (2015) y "Gobernabilidad universitaria: las primeras luchas por el cogobierno universitario en Colombia”, en Revista Pedagogía y Saberes No. 40 (2014). Entre sus temas de interés están historia de los movimientos sociales e historia de la educación.
\end{abstract}

Recibido: 2 de septiembre de 2014

Aprobado: 22 de octubre de 2015

Modificado: 5 de noviembre de 2015

Artículo de investigación científica

DOI: http://dx.doi.org/10.15648/hc.28.2016.6

Este artículo forma parte del proyecto: “¿Colombia indignada?: estudiantes y movilización por la educación superior, 2011. Un análisis histórico-retrospectivo”, financiado por la Universidad Industrial de Santander (Colombia).

Esta publicación está bajo una licencia Creative Commons Reconocimiento-NoComercial 4.0 


\title{
Ideología revolucionaria y sociabilidad política en los grupos universitarios maoístas de los años 60 y 70 en Colombia
}

\section{Resumen}

El presente artículo investiga la historia de la ideología revolucionaria de los grupos universitarios maoístas en Colombia, con referencia a su sociabilidad política. Se trata de agrupaciones creadas por jóvenes universitarios para organizar acciones hacia el cambio social. El trabajo realizado se apoya en una reflexión investigativa sobre los movimientos estudiantiles y el gobierno universitario en Colombia en los años 60 y 70 y en una serie de recopilaciones y estudios documentales realizados por el CINEP sobre las izquierdas sociales y políticas. Diversas agrupaciones de izquierda, en disputa por controlar la gobernabilinidad universitaria, hicieron presencia en los campus universitarios para desde allí propiciar acciones de cara a los desafíos de transformar la sociedad, sobre el entendido de cambiar la institucionalidad educativa como fase previa a la revolución socialista, según las distintas tendencias ideológicas del amplio espectro de la izquierda mundial y nacional.

Palabras clave: ideología, maoísmo, revolución, sociabilidad política.

\section{Revolutionary ideology and sociability policy in university maoists groups from the 60's and 70's in Colombia}

\begin{abstract}
This article researches the revolutionary ideology history of the Maoists university groups in Colombia, related to his political sociability. This is a group set up by university students in order to organize actions towards social change. This work is supported by a research reflection on the university student movements and government in Colombia in the 60s and 70s, and in a series of collections and documentary studies by the CINEP on the social and political left-wing. Various left-wingers groups, in dispute over control the university governance, were present on university campuses to promote actions facing the challenges of transforming society on the basis of an understanding the educational institutions changing, as a preliminary phase to the socialist revolution. According to the different ideological trends of a global and national left broad spectrum.
\end{abstract}

Key words: ideology, Maoism, revolution, political sociability. 


\section{Ideologia revolucionária e sociabilidade política em grupos universitários maoístas dos anos 60 e 70 na colômbia}

\section{Resumo}

Este artigo investiga a história da ideologia revolucionaria dos grupos universitários maoístas na Colômbia, com referência a sua sociabilidade política. Trata-se de agrupações criadas por jovens universitários para organizar ações de mudança social. O projeto se apoia em uma reflexão investigativa sobre os movimentos estudantis e o governo universitário na Colômbia nos anos 60 e 70, e em uma série de recolecções e estudos documentais realizadas pela CINEP sobre as esquerdas sociais e políticas. Vários grupos de esquerda, em disputa por controlar a governabilidade universitária fizeram presença em campus universitários para propiciar ações de cara aos desafios para transformar a sociedade, sobre o acordo de mudar a institucionalidade educativa como fase previa à revolução socialista, segundo as diversas tendências ideológicas do amplo espectro da esquerda mundial e nacional.

Palavras chave: ideologia, maoísmo, revolução, sociabilidade política.

\section{Idéologie révolutionnaire et sociabilité politique chez les groupes universi- taires maoïstes des années 60 et 70 en Colombie}

\section{Résumé}

Cet article examine l'histoire de l'idéologie révolutionnaire des groupes universitaires maoïstes en Colombie, par rapport à sa sociabilité politique. Il s'agit de groupes créés par des jeunes universitaires pour organiser des actions visant le changement social. Le travail accompli s'appuie sur une recherche faite sur le mouvement étudiant et le gouvernement universitaire en Colombie des années 60 et 70, et sur une série de compilations et d'études documentaires menées par le CINEP sur les gauches sociales et politiques. De différents groupes de gauche, en dispute pour le contrôle de la gouvernabilité universitaire, ont fait présence dans les campus pour y encourager des actions vis-à-vis des défis de transformer la société, y compris le changement de l'institutionnalité éducative comme étape préalable à la révolution socialiste, d'après les différentes tendances idéologiques du vaste spectre de la gauche mondiale et nationale.

Mots clés: idéologie, maoïsme, révolution, sociabilité politique. 


\section{INTRODUCCIÓN}

En Colombia como en otros lugares del mundo durante los decenios de 1960 y 1970 primó un ambiente de lucha revolucionaria. Los líderes sindicales, los antiguos militantes del Partido Comunista, algunos literatos y artistas de avanzada y los jóvenes universitarios fueron atraídos en lo ideológico, emocional y político por las corrientes discursivas que abogaban por una revolución total. No fueron pocos los grupos de izquierda que surgieron tras las revoluciones china y cubana o por el fuerte influjo del Mayo Francés. Todo este movimiento social, político e intelectual hizo sin duda pensar a esta generación que los cambios históricos deseados eran posibles si se creaban organizaciones capaces de dirigir la lucha revolucionaria, así que no dudaron en crear al interior de las universidades grupos destinados a estudiar y difundir las ideologías en boga y a organizar acciones políticas concretas en pro de la revolución como movilizaciones, mítines, marchas o debates.

Las organizaciones estudiantiles, sus manifestaciones, sus protestas y en general sus acciones públicas han sido entendidas como una expresión palpable de lo que constituye un movimiento social. Para referirlas y estudiarlas se habla, en consecuencia, de los movimientos estudiantiles. Tomando como punto de partida las categorías de movimiento social y sociedad civil $^{1}$; el movimiento estudiantil es considerado una expresión organizativa de un sector social: el estudiantado. En este sentido, y tal como sucede con cualquier movimiento social, los movimientos estudiantiles han sido definidos como los escenarios en que se expresan los intereses particulares y colectivos de los sujetos en relación de complementariedad, oposición o negociación con el Estado y las instituciones políticas ${ }^{2}$. Una mirada como esta, sin embargo, deja por fuera muchas de las prácticas sociales o políticas que también caracterizan a los movimientos estudiantiles, como lo es la tendencia de los universitarios a crear sus propias asociaciones -formales

1 Estas nociones han sido trabajadas desde muchas orillas teóricas; luego un abordaje exhaustivo de las mismas rebasa los objetivos de esta introducción. Pueden mirarse los estudios de autores como Sidney Tarrow, Alain Touraine y Alberto Melucci sobre los movimientos sociales.

2 Luis Alberto Restrepo, El potencial democrático de los movimientos sociales y de la sociedad civil en Colombia (Bogotá: Corporación Viva la Ciudadanía, 1993), 15-32. 
e informales- como espacios de estudio y debate de ideas alrededor de las cuales definen su universo político e ideológico, ya que desde el enfoque sociológico y político no se logra percibir ni la variabilidad interna de los movimientos sociales ni la microdinámica que los constituyen, al priorizar la homogeneidad sociológica y política. Estos análisis también dejan por fuera el estudio de las identidades, las relaciones y las trayectorias sociales de los miembros de las agrupaciones de universitarios, así como la historia de las prácticas asociativas como ámbitos para la definición de lazos políticos durante un momento revolucionario. Es por esta razón que, en el presente artículo se propone un acercamiento a la sociabilidad política de los grupos universitarios de las décadas de 1960 y 1970 en Colombia.

Como se sabe, los estudios de las formas de sociabilidad han privilegiado el periodo histórico de la transición hacia la modernidad, ya que la sociabilidad es en sí misma una manifestación política moderna. Esto no significa que el concepto sea una noción exclusiva de la primera etapa republicana, pues puede ser utilizado como un concepto analítico, según lo ha expresado González Bernaldo, susceptible de ser utilizado como una herramienta heurística para el estudio de sociabilidad asociativa, sobre todo porque la sociabilidad "remite a prácticas sociales que ponen en relación un grupo de individuos que efectivamente participan de ellas"3, y estos fenómenos sociales suelen presentarse en distintas épocas de la historia republicana, tal como sucedió durante las décadas del 60 y 70 con las asociaciones estudiantiles.

El análisis emprendido en este estudio se apoya, entonces, en el concepto analítico de sociabilidad, es entendida en los siguientes términos: en primer lugar se caracteriza por ser un tipo de asociación de carácter elástico, ya que conecta aspectos de la vida cultural con aspectos de la vida política, y porque vincula la utilización del tiempo libre con la tendencia a la institucionalización de algunas prácticas sociales, como las reuniones de miembros. En segundo lugar, la sociabilidad se relaciona con los factores ideo-

3 Pilar González Bernaldo, "La sociabilidad y la historia política”, en: Nuevo Mundo Mundos Nuevos [En línea], Puesto en línea el 17 febrero 2008. BAC - Biblioteca de Autores del Centro, http://nuevomundo.revues.org/24082 
lógicos, científicos, culturales, o tecnológicos que pueden generar cambios en la vida pública de una época, pues las agrupaciones de personas suelen utilizar estos factores como elementos que justifican la asociación o la impulsan. Y en tercer lugar, la sociabilidad política es "una expresión genuina" de la "competición despiadada por la hegemonía en la vida pública". Es entonces, "uno de tantos instrumentos" de competición política ${ }^{4}$.

Esta manera de entender el concepto de sociabilidad permitirá comprender el comportamiento de los centenares de jóvenes que formaron parte de los grupos maoístas surgidos en las universidades durante el periodo de estudio. Los estudiantes universitarios colombianos de la década del 70 no tenían una organización gremial de alcance nacional como la que existió en los años 60 con la Federación Universitaria Nacional (FUN), pero en las regiones y en las universidades surgieron estructuras organizativas que aglutinaban a los estudiantes, tal como sucedía en Santander con la Asociación de Estudiantes Universitarios de Santander (AUDESA) o en el Valle del Cauca con la Federación de Estudiantes de la Universidad del Valle (FEUV). Todos estos grupos eran espacios de sociabilidad política adscritos a una corriente particular de la ideología revolucionaria occidental. De ahí que existieran grupos marxistas, leninistas, maoístas o trotskistas. Para comprender la historia de estos grupos es necesario prestar atención a sus espacios de sociabilidad política. Hecho que permitirá entender no solo la radicalización ideológica experimentada por esta generación de colombianos, sino el papel político que la universidad desempeñó en aquellos tiempos al constituirse en un campo propicio para la difusión de las ideas revolucionarias y la creación de organizaciones armadas.

Aquellos grupos replicaban en la universidad las mismas divisiones que la ideología revolucionaria expresaba fuera de ella. El Partido Comunista, por ejemplo, organizó desde 1951 la Juventud Comunista (JUCO); el Movimiento Obrero Independiente Revolucionario (MOIR) propició al poco tiempo de su creación la Juventud Patriótica (JUPA); el campo maoísta contó con organizaciones como la Liga Marxista-Leninista (LML); los

4 Gilberto Loaiza Cano, Sociabilidad, religión y política en la definición de la nación colombiana, 18201886 (Bogotá: Universidad Externado de Colombia, 2011), 22, 27. 
trotskistas surgieron del seno universitario, mientras que el camilismo devino en los llamados Comandos Camilistas (CC). Estos grupos tuvieron presencia en varias de las universidades públicas y privadas del país y sirvieron de punta de lanza en la organización de las protestas, marchas, mítines y confrontaciones con la fuerza pública, las autoridades universitarias y políticas.

La historia de estas agrupaciones universitarias de izquierda en el país está aún por escribirse. Luego del trabajo de Gerardo Molina sobre las ideas socialistas en Colombia o la investigación de Fabio López De la Roche sobre la cultura política de las izquierdas colombianas, la reflexión sobre este tema de estudio no ha estado a la orden del día ${ }^{5}$. En su lugar, ha llamado más la atención de los investigadores el tema de la izquierda armada o de los diferentes grupos guerrilleros, debido, entre otras razones, a la vigencia del conflicto armado ${ }^{6}$. Por esta razón, el presente artículo se propone abordar la historia de la ideología revolucionaria de los grupos universitarios maoístas en referencia aproximativa a su sociabilidad política, pues se trataba de agrupaciones creadas por jóvenes universitarios para debatir ideas y organizar acciones en pro de la revolución. El presente trabajo se apoya, específicamente, en una serie de estudios realizados por el CINEP sobre las izquierdas sociales y políticas ${ }^{7}$. Hay que señalar que no se trata de una historia institucional de estas formas de asociación, sino de una aproximación a sus discursos ideológicos y a la caracterización de sus prácticas sociales.

5 Gerardo Molina, Las ideas socialistas en Colombia (Bogotá: Tercer Mundo, 1987). Fabio López de la Roche, Izquierdas y cultura política: ¿oposición alternativa? (Bogotá: CINEP, 1994).

6 Recientemente, los estudios sobre las Fuerzas Armadas Revolucionarias de Colombia (FARC) y el Ejército de Liberación Nacional (ELN) tuvieron un resurgimiento interesante, especialmente, por los enfoques de análisis. Lamentablemente, predomina el estudio de su ya larga duración y las mutaciones en su lucha armada. Ver: Eduardo Pizarro León-Gómez, Las FARC 1949-2011: de guerrilla campesina a máquina de guerra (Bogotá: Norma, 2011). Carlos Medina Gallego, FARC-EP: temas y problemas nacionales. 1958-2008 (Bogotá: Universidad Nacional de Colombia, s.f.). Carlos Medina Gallego, "FARC-EP: notas para una historia política, 1958-2006" (tesis de Doctorado en Historia, Universidad Nacional de Colombia, s.f.). Carlos Medina Gallego, "ELN-Ejército de Liberación Nacional: notas para una historia de las ideas políticas: 1958-2007” (tesis Doctorado en Historia, Universidad Nacional de Colombia, s.f.).

7 Mauricio Archila, Una historia inconclusa: izquierdas políticas y sociales en Colombia (Bogotá: CINEP/COLCIENCIAS, 2009). 


\section{La eXpansión del maoísmo en Colombia}

Si la nueva izquierda tuvo una expresión fuerte en las décadas de los 60 y 70 fue debido a la creación de una corriente y un proyecto político alternativo al socialismo soviético en la China de Mao Tse Tung. La crítica al burocratismo y la coexistencia pacífica con el capitalismo, tesis propuestas por Moscú luego de la muerte de Stalin, fue una de las principales banderas de la experiencia china liderada por el Partido Comunista Chino (PCCh) y el "gran timonel" como se le conoció en la época a Mao. El triunfo de la Revolución China en 1949, luego de una larga guerra revolucionaria, catapultó a Mao no tanto como un teórico alternativo del marxismo, sino como un realizador exitoso del materialismo histórico. En efecto, más que un recreador de las tesis de Marx-Engels, como lo fueron Gramsci, Luckács, Korsch o la misma Luxemburgo, Mao fue un educador y polemista, cuyo más importante pergamino fue haber dirigido una revolución socialista en el país más poblado de la tierra. Formado en el marxismo-leninismo de raíz estalinista, instauró un régimen que denominó de "nueva democracia" como un estadio de transición al socialismo en el que la burguesía nacional tenía un papel progresista para liquidar las fuerzas feudales remanentes ${ }^{8}$.

Tras intentar acercamientos en busca de cooperación con la Unión de Repúblicas Socialistas Soviéticas (URSS), la China de Mao propició a principios de los años 60 una gran ruptura e impulsó en todo el mundo la creación de partidos comunistas "marxistas-leninistas". Con el establecimiento de la famosa Revolución Cultural a partir de 1966, la vía china al socialismo ganó un gran prestigio a nivel internacional, al punto que las imágenes de Mao acompañaron las de Marx, Engels y Lenin en las banderas y carteles de los jóvenes europeos durante las jornadas de Mayo del 68. La buena imagen internacional contrastaba con los fracasos que en materia económica tuvo el régimen en la década anterior, especialmente en la colectivización de la economía campesina que derivó en una gran hambruna entre 1959 y 1961. Incluso la gran campaña a nivel ideológico y cultural que entrañó la Revolución Cultural para eliminar cualquier rasgo "burgués" en el arte y la cultura, significó también el alejamiento de China

8 Philip Short, Mao (Barcelona: Crítica, 2011). 
de cualquier modernización. Esta fue una muestra del marcado misticismo y de la ortodoxia que caracterizó al maoísmo, rasgos que se impondrían en las versiones colombianas.

La expansión de la corriente maoísta por todo el continente se caracterizó por dos elementos claves en la renovación del proyecto revolucionario en la segunda mitad del siglo XX. Con diez años de anticipación a la Revolución Cubana, el triunfo de Mao posicionó la lucha armada como la principal forma de lucha revolucionaria; más aún en tiempos en que los soviéticos habían desistido de impulsar el socialismo a nivel mundial para hacer realidad la tesis de Stalin de la revolución en un solo país. Por otra parte, el escenario más importante para realizar la revolución era el campo, retomando la exitosa experiencia china. Sin embargo, a diferencia de la experiencia cubana, el caso chino enseñó que el aparato armado debía estar supeditado al partido, que a su turno debían articularse a un frente popular de masas. Los grupos políticos que se crearon en torno a la figura y el pensamiento de Mao ensayaron diferentes combinaciones y grados de fidelidad respecto a la experiencia china, siguiendo el cisma internacional que afectó al campo socialista en los años 60 y que formalizó la creación de una nueva izquierda en todo el orbe. La adhesión a uno de los referentes socialistas ayudó a incrementar la pugnacidad propia de la izquierda colombiana, demostrando cada quien mayor o menor grado de dogmatismo. El maoísmo se estructuró a partir del odio visceral a la URSS y al Partido Comunista Colombiano (PCC) y acuñó el término 'mamerto' para identificar a uno de los enemigos a los que tenía que combatir?.

\section{LAS ORGANIZACIONES MAOÍSTAS}

Entre 1971 y 1973 la nueva izquierda universitaria conoció una conjunción de grupos y proyectos políticos, todos de raíz maoísta, llamada Corriente Marxista Leninista (CML) que aglutinó a la Unión Proletaria (UP), el Núcleo Marxista Leninista (NML) y la Unión Comunista Revolucionaria

9 Mauricio Archila, "El maoísmo en Colombia: la enfermedad juvenil del marxismo-leninismo", en Una historia inconclusa: izquierdas políticas y sociales en Colombia, Mauricio Archila (Bogotá: CINEP/Colciencias, 2009), 179-183. 
(UCR). Con influencia durante casi toda la década del 70, la UP logró un importante posicionamiento en el interior de la universidad colombiana, en regiones como Cundinamarca, Tolima, Meta y Santander. Entre sus prioridades políticas, además de reafirmar cotidianamente su adhesión a las verdades que Mao había señalado en sus tesis filosóficas, esperaban vincularse ideológica y políticamente al proletariado industrial, ligarse a las masas campesinas, en especial al proletariado agrícola para desarrollar una organización política con ellos y, como era obvio, lograr la aplicación de las "verdades universales" del Marxismo-Leninismo-Maoísmo en "situaciones concretas". Como parte de este proceso, este grupo también se acercó a la Asociación Nacional de Usuarios Campesinos (ANUC), específicamente a los Comités de Educación, mientras que en la ciudad lograron la organización de los primeros sindicatos de vendedores ambulantes. Para 1980 y luego de un acercamiento al mundo electoral como parte del Frente por la Unidad del Pueblo que agrupaba varios núcleos maoístas, tanto la UP como la Liga ML desaparecieron de la escena política nacional.

Otro de los grupos pertenecientes al campo maoísta en Colombia respondía al nombre de Organización Revolucionaria del Pueblo (ORP), profundamente vinculado a la ANUC Línea Sincelejo. Encabezado por Alfonso Cuéllar y Miguel Gamboa y bajo la influencia de Orlando Fals Borda, esta corriente maoísta alcanzó a tener incidencia en el nivel dirigente de la ANUC a través de la Comisión Central Impulsora o Comisión Política. Tal instancia tuvo en 1972 la tarea de acompañar y orientar política e ideológicamente a la organización campesina. La pretensión de llevar la lucha de los usuarios campesinos, más allá de las reivindicaciones gremiales como un primer paso en el proceso revolucionario, ocasionó el señalamiento de la Comisión Política como anarcosindicalista que terminaría en 1977 con la creación de la Organización Revolucionaria del Pueblo (ORP). Más que crear un partido campesino como tal, lo que pretendía esta era la organización de un frente de masas en el que se aglutinaran obreros, estudiantes, intelectuales y campesinos. Criticados por otros grupos marxistas leninistas como el Comando Pedro León Arboleda (PLA), se llegó al punto de afirmar que Fals Borda era agente de la Central Intelligence Agency (CIA) y declaró objetivo militar a todo el Comité Ejecutivo de la ANUC. En la segunda mitad de los 70, la ORP se acercó a la lucha electoral y, como la 
totalidad de las organizaciones maoístas, terminó dividiéndose de acuerdo a las corrientes en que se fracturó la $\mathrm{ANUC}^{10}$.

De todos los grupos en que el maoísmo vivió atomizado en Colombia solo un proyecto político se mantiene hasta nuestros días como parte del escenario de la izquierda colombiana. Nos referimos al MOIR que contó desde un inicio con un ala juvenil llamada JUPA. El nacimiento del MOIR estuvo directamente ligado al liderazgo y papel de Francisco Mosquera en el marco del Movimiento Obrero Estudiantil Campesino (MOEC), al punto que se puede afirmar que el MOIR fue una derivación de una de las primeras experiencias políticas de la nueva izquierda en nuestro país. Una de las principales identificaciones del movimiento creado por Mosquera el 14 de septiembre de 1969, fue la "toma distancia" del dogma de la época concerniente en asumir la lucha armada como la máxima forma de lucha. El MOIR representó un caso particular de formación política, puesto que inicialmente no fue concebido como un movimiento y mucho menos como un partido político como tal sino como una plataforma en la que confluyeron sectores de un sindicalismo independiente tanto de la égida de los partidos tradicionales como de la confederación que controlaba el Partido Comunista Colombiano (PCC).

Sobre su fundador, Francisco Mosquera, únicamente hasta hace un par de años se ha realizado un acercamiento a su trayectoria política, bajo la idea de la transición de un joven liberal que mutó su ideario y práctica política hacia la izquierda maoísta. Siguiendo a Abelardo Díaz, hay que señalar que Mosquera fue un joven periodista que, gracias a Alejandro Galvis, obtuvo un espacio en el periódico santandereano Vanguardia Liberal, el cual aprovechó para incursionar en asuntos públicos y colectivos. Desde sus columnas semanales, este bachiller del Colegio Santander - del que salieron también otros líderes políticos como Jaime Arenas- recibió denuncias de la ciudadanía acerca de problemas barriales y criticó la dirigencia liberal por su falta de voluntad para resolver los de la gente de Santander y del

10 Frank Molano, "La izquierda maoísta colombiana: organizaciones y mentalidades en la década de 1970" en: Para reescribir el siglo XX: memoria, insurgencia, paramilitarismo y narcotráfico, editado por Olga Yanet Acuña Rodríguez y Javier Guerrero Barón. Medellín: La Carreta/UPTC, 2011, 361 371. Mauricio Archila, "El maoísmo en Colombia...", 187-192. 
país. En sus escritos periodísticos, este joven político manifestó inquietudes frente a temas importantes como la reforma agraria y llegó a simpatizar con las reivindicaciones de los campesinos. Igualmente expresaba, a sus 18 años, un interés por la figura de Francisco de Paula Santander y su significado para el liberalismo colombiano.

Tras concluir sus estudios de bachillerato, Mosquera viajó a Bogotá a adelantar estudios de Derecho, circunstancia que le permitió acercarse a las ideas de izquierda y asumir nuevos compromisos políticos que lo llevaron a radicalizar su posición frente a las injusticias sociales. Para 1961, su ruptura con el liberalismo era un hecho; sin embargo, mantuvo una posición crítica con la fiebre militarista derivada del triunfo de la Revolución Cubana. Como cuadro del MOEC, también cumplió una importante labor formadora de militantes entre 1963 y 1965, años en los que decidió abandonar sus estudios y dedicarse de lleno a la acción política. Dentro del MOEC la crisis permanente permitió que se destacara su voz disidente, particularmente en temas como la falta de preparación ideológica y el excesivo peso atribuido a la lucha armada. Para 1965 y todavía como parte del MOEC, durante una reunión nacional de cuadros expresó la necesidad de crear un auténtico partido leninista, dedicado a adelantar un verdadero trabajo de masas. Debido a las constantes críticas al militarismo del MOEC, sectores "guerrilleristas" lo amenazaron de muerte obligándolo a trasladarse a Medellín, ciudad en la que su carrera política tomaría nuevos rumbos.

En la capital antioqueña logró insertarse en el sindicalismo independiente a través de algunos militantes del MOEC que lo seguían y que compartían sus tesis. Allí se vinculó inicialmente con el Sindicato de las Empresas Públicas de Medellín y luego asesoró una huelga en una empresa de calzado, hecho que le ganó prestigio en otros sectores. A principios de 1968 los obreros de la explotación carbonífera con sede en Amagá realizaron un paro en el que Mosquera tuvo un papel importante, lo cual le llevó a ser detenido en dos oportunidades. La visión acerca de la creación de una nueva vanguardia revolucionaria articulada a la mayor cantidad de conflictos laborales en el país y el relativo éxito alcanzado en Antioquia, le permitió a él y al MOEC extender su influencia a otros departamentos, entre los que se destacaron Valle del Cauca y Santander. Crítico de la Confederación de 
Trabajadores de Colombia (CTC), la Unión de Trabajadores de Colombia (UTC) y la Confederación Sindical de Trabajadores de Colombia (CSTC) -centrales sindicales afines al bipartidismo, las dos primeras, y expresión del revisionismo criollo la última- decidieron realizar un Encuentro $\mathrm{Na}$ cional del Sindicalismo Independiente entre el 12 y 14 de septiembre de 1969. A este evento asistieron el Bloque Sindical Independiente de Antioquia y Santander, el Frente Sindical Autónomo del Valle, la Unión Sindical Obrera (USO) recién desafiliada de la CSTC, la Federación Nacional de Transportadores de Carga (FENALTRACAR) y la Federación de Trabajadores de las Empresas Petroleras (FEDEPETROL). También participaron sectores políticos ligados al camilismo, el trotskismo y dirigentes como Diego Montaña Cuéllar.

El 14 de septiembre de 1969 se creó oficialmente el MOIR, concebido inicialmente como una central sindical en la que confluyeron varios sectores de la nueva izquierda. Las tensiones y divisiones no se hicieron esperar y un año más tarde quedaron solamente sectores ligados a Mosquera y al MOEC, escisión que se hizo oficial en el Pleno de Cachipay en 1970, evento en el que inició el camino de la construcción de un nuevo partido de izquierda, inspirado en las tesis del maoísmo y en la crítica al "revisionismo" de origen soviético ${ }^{11}$. Según Frank Molano, quien ha estudiado el maoísmo en Colombia con mayor detenimiento, el MOIR resolvió el debate sobre la pertinencia de crear un partido, un ejército o un frente de masas común entre la izquierda prochina de aquellos años, a través de la creación de un frente de masas cuyo deber ser era la lucha reivindicativa y política del proletariado colombiano ${ }^{12}$.

A diferencia del resto de organizaciones maoístas de la época, el MOIR no resolvió su trabajo con el campesinado en el marco de la ANUC. En su lugar, creó la Organización Independiente y Revolucionaria (OCIR) que nunca tuvo desarrollo. La valoración que hizo del auge de luchas campe-

11 José Abelardo Díaz Jaramillo, "Del liberalismo al maoísmo: encuentros y desencuentros políticos en Francisco Mosquera Sánchez, 1958-1969”, Anuario Colombiano de Historia Social y de la CulturaVol. 38 No. 1 (2011): 141-176.

12 Una revisión desde el maoísmo de la trayectoria política del PC, en: ¿De dónde venimos, hacia dónde vamos, hacia dónde debemos ir? (Medellín: Editorial 8 de junio, 1975), 390-420. 
sinas y estudiantiles en los primeros años de la década del 70 no fue la de una situación revolucionaria, como sí lo hicieron otros grupos. Sin embargo, el mayor distanciamiento respecto a los demás grupos maoístas y, en general, de la nueva izquierda fue el abandono de sus tesis abstencionistas en 1972, hecho que le granjeó el epíteto de oportunista. Además de crítico de la lucha armada como la forma de lucha prioritaria en la construcción del socialismo en Colombia, el MOIR se caracterizó desde temprano por acudir a la lucha electoral, para lo cual hizo parte de la Unión Nacional de Oposición (UNO) entre 1972 y 1975 junto con el PC y creó el Frente por la Unidad del Pueblo (FUP) entre 1976 y 1978. Finalmente, el MOIR ganó una considerable base social en el marco del maoísmo, debido a la campaña de los descalzos ejecutada en el decenio de los 70. En pocas palabras, la dirección del movimiento envió a sus militantes "pequeñoburgueses" e intelectuales a vincularse a las masas campesinas y proletarias para que convivieran con ellas. El abandono de su condición social acomodada implicó grandes sacrificios que afectaron la vida privada de sus militantes, más allá de los objetivos de organización de las masas para las elecciones, la guerra popular prolongada contra el imperialismo y la oligarquía ${ }^{13}$.

\section{Las sociabilidades políticas del campo maoísta en Colombia}

La nueva izquierda en general y el maoísmo en particular contaron entre sus miembros con un importante número de jóvenes, quienes ingresaron a los grupos, movimientos y partidos, al calor de la agitación de estas dos décadas. En algunos casos, la efervescencia revolucionaria empezó desde el colegio o en el hogar con la influencia de un profesor afín a las ideas de izquierda o a través de la antigua militancia de sus padres o familiares próximos. Es este tipo de fenómenos lo que puede ser considerado una sociabilidad política. En el maoísmo, al parecer, gran parte de su militancia provenía de las capas medias de provincia, condición que impedía el acceso a una cultura cosmopolita. En cuanto al género, la presencia de mujeres no fue muy común en las filas del campo Marxista Leninista (ML), situación que evidenciaba el peso de las estructuras patriarcales y la rigidez

13 Frank Molano, La izquierda maoísta colombiana, 371-373. Mauricio Archila, "El maoísmo en Colombia”, 192-193. 
de la separación de los géneros a pesar de la proclamación abstracta de la igualdad. En cuanto a las bases sociales de la miríada de grupos marxistas-leninistas, por convicciones ideológicas tuvieron mayor arraigo entre los campesinos, aunque también contaron con presencia en sindicatos de empleados como los bancarios, estatales y maestros. Otros sectores en los que pudieron desarrollar trabajo político fueron en su orden: el estudiantil, los vendedores ambulantes y los invasores de terrenos. En vista que el objetivo era la "guerra popular prolongada", la lucha por reformas y el trabajo con estas bases asumió un carácter instrumental. He allí una de las diferencias estructurales entre el MOIR y el resto de grupos.

Respecto a los principales contenidos del discurso maoísta, es necesario subrayar la entronización que hicieron todos los grupos de la lucha armada. No puede decirse que la izquierda desde el mismo siglo XIX en Europa se hubiese mantenido ajena a la reivindicación de la violencia política como "partera de la historia". A diferencia de la experiencia rusa con su modelo insurreccional y del foquismo cubano, el maoísmo proclamó la guerra popular prolongada como estrategia al mando del partido. Es decir, la lucha política estaba llamada a orientar la lucha militar y la organización progresiva de las masas. En nuestro país diferentes organizaciones maoístas subordinaron lo político a lo militar, e incluso el MOIR inicialmente justificó el uso de la violencia revolucionaria.

La nueva izquierda, especialmente aquella afín al marxismo-leninismo, se destacó por su dogmatismo. En el caso del maoísmo, este atributo fue llevado hasta el paroxismo al proclamarse seguidores del "pensamiento Mao Tse-Tung”. Aura María Puyana Mutis recuerda, por ejemplo, cómo llegó al maoísmo:

"Desde el año 69-70 nosotros ya nos declaramos ateas y de izquierda y ya teníamos contactos de otros colegios [...]Y tres o cuatro jesuitas muchachos que nos apoyaron, varios de los cuales militan en la izquierda y todavía nos escribimos con ellos [...]En principio de los 70 surge el MOIR, un movimiento de izquierda con orientación muy obrerista, muy sindical pero deslindado de la lucha obrera con una división del MOEC, Movimiento Obrero 
Estudiantil Campesino y en Pasto coge mucha fuerza [...] Entonces yo empiezo a trabajar con ellos y empezamos a ser un grupo de estudio del colegio y nunca me expulsaron las monjas. Todos los pupitres llenos de "Pekin Informa" y de "China Ilustrada" que llegaba por toneladas en esa época, llegaban por toneladas revistas chinas. Entonces yo las repartía y teníamos un grupo de estudio y nos volvimos maoístas ahí estaba Clara Inés Guerrero, Melba Cristina Benavidez, Josefina Cano, Lucía Silva, María Eugenia Vásquez y yo"14.

Si ellos eran los verdaderos y únicos herederos de las enseñanzas de Marx, Lenin y Stalin, mejoradas y ampliadas por la práctica política del líder chino, los demás grupos podían ser señalados y marcados con el calificativo de "revisionistas". Esta expresión hizo parte de la jerga cotidiana de los militantes maoístas y de izquierda en general, y se acuñó para evidenciar las desviaciones de la "ciencia del proletariado". Los ML salían y gritaban, nos recuerda Aura María Puyana: "Mientras no cambie el sistema, no cambiará la educación. Abajo los revisionistas y reformistas y los "mamertos". Abajo la JUCO, abajo la JUCO"15. Los miembros del Partido Comunista, coloquialmente llamados "mamertos", fueron el blanco preferido de los maoístas. En el fragor de las disputas puristas incluso se llegó a llamar revisionistas y oportunistas a los otrora compañeros de lucha que llegaron a dudar del dogma. Si bien el dogmatismo no fue patrimonio exclusivo del campo ML, este llegó a presentar variaciones importantes, especialmente por aferrarse al "pensamiento" de la figura carismática de Mao. Más que el culto a la personalidad practicado con Stalin, los maoístas consideraban a Mao casi como una deidad, lo que explica el sentimiento de orfandad y confusión tras su muerte.

La solución de los conflictos internos o con otros grupos de izquierda que manifestaran un desacuerdo en el diagnóstico de la situación política se expresó con un lenguaje militar. La idea de traición fue moneda corriente

15 Entrevista realizada por Laura Cadena Castro a Aura María Puyana Mutis el 23 de febrero de 2010. 
en aquellos años. Para las diversas organizaciones maoístas los principios ideológicos representaban no solo la posibilidad de una acción política "correcta" sino la explicación de la realidad en sus más profundas leyes. Dotarse de una ideología clara y sin baches a través de la lectura de las citas del presidente Mao o sus Cinco tesis filosóficas, posibilitaba al militante obviar las llamadas "condiciones objetivas" necesarias para la revolución e imbuirse en un compromiso revolucionario lleno de voluntarismo subjetivista. Más que conocer el país y su realidad, era más importante el alineamiento internacional en las grandes corrientes socialistas. Los activistas y vanguardistas de izquierda se sentían los conductores de la humanidad hacia paraísos de caña y miel, para lo cual las bases estaban obligadas a seguir la verdad revelada contenida en las cartillas del marxismo-leninismo.

A mediados de los años 70 algunos sectores del maoísmo colombiano decidieron emprender un acercamiento a la historia y a la realidad colombiana y así evitar el traslado mecánico de categorías elaboradas para interpretar la historia china. Este viraje tuvo un impacto positivo en el desarrollo de las Ciencias Sociales en Colombia, especialmente en la labor editorial que se desplegó, pues los sellos que se crearon permitieron la difusión de investigaciones dedicadas a temas agrarios, políticos, culturales, históricos y económicos. Editoriales como La Pulga (Medellín: 1967-1976), Hombre Nuevo (Medellín: 1964-1980), 8 de junio (Medellín: 1975) y las primeras fases de la Oveja Negra (Medellín: 1969), son algunos ejemplos. El maoísmo concretamente publicó revistas como Uno en Dos y Revista de Revistas, mientras que el MOIR creó el Centro de Estudios sobre el Trabajo en Colombia (CEDETRABAJO) con su revista Deslinde.

En cuanto al diagnóstico que hizo el campo ML sobre la realidad colombiana, base fundamental para acometer la lucha revolucionaria, la tendencia general fue la de no aceptar que el país era capitalista plenamente. Los conflictos en el campo y la edificación de lo rural en el pensamiento maoísta los llevaron a catalogar a la sociedad colombiana como poseedora de remanentes feudales. Estos eran obstáculos para emprender inmediatamente la construcción del socialismo en Colombia, tal y como sí lo consideraban los trotskistas y filocubanos. Por tanto, el sendero a transitar era 
el de una revolución de Nueva Democracia ${ }^{16}$ que permitía crear alianzas con sectores progresistas de la burguesía nacional. Esta concepción era compartida, por ejemplo, entre el MOIR y el PC, no así con el PC-ML y otros núcleos más radicales que no reconocían la existencia de esa supuesta fracción progresista de la burguesía nacional. En muchas ocasiones las diferencias entre los distintos grupos ML tenían, en la base, análisis de la realidad más o menos cercanos a la doctrina maoísta original.

Convencidos de la necesidad de suprimir cualquier diferencia entre el saber y el hacer, tal y como lo había sostenido Mao, los grupos pro-chinos defendieron una igualdad radical que rayaba en el igualitarismo. Muestra de ello fue la pretensión por uniformarse en el vestir, la desconfianza y sospecha en el mundo intelectual y la cultura occidental y la sobrevaloración de la experiencia, siguiendo la máxima de Mao de que todo conocimiento se derivaba de la práctica. El maoísmo pretendió extirpar los rezagos feudales de la sociedad colombiana y, al tiempo, los rasgos "burgueses" de sus militantes. Para ello esgrimieron una defensa de lo "oriental", que constituyó una primera invocación de una subalternidad radical adelantándose a los estudiosos de India. "En la teología maoísta había prácticas religiosas para uno purgar las culpas", como "ir a cine con una novia" en vez de cumplir con "una tarea revolucionaria" -nos cuenta Armando Martínez Garnica, en una entrevista personal-. Por ese pecado "tuve que ir a pintar en la pared, luego me confesaba mi culpa y me ponía como penitencia leer uno de los cinco permanentes de Mao Tse-Tung"17. Si se trata de comprender este tipo de comportamiento, el autor puede remitirse a casi toda la obra

16 Por revolución de nueva democracia Mao entendía una revolución antiimperialista y antifeudal de las grandes masas populares bajo la Dirección del proletariado: "En su primera etapa o primer paso, tal revolución de un país colonial o semicolonial, aunque por su carácter social sigue siendo fundamentalmente democrático-burguesa y sus reivindicaciones tienden objetivamente a desbrozar el camino al desarrollo del capitalismo, ya no es una revolución de viejo tipo, dirigida por la burguesía y destinada a establecer una sociedad capitalista y un Estado de dictadura burguesa, sino una revolución de nuevo tipo, dirigida por el proletariado y destinada a establecer, en esa primera etapa, una sociedad de nueva democracia y un Estado de dictadura conjunta de todas las clases revolucionarias. Por consiguiente, esta revolución abre precisamente un camino aún más amplio al desarrollo del socialismo". Mao Tse-tung, "Sobre la nueva democracia", en Obras Escogidas de Mao Tse-tung, Pekín Tomo II, Ediciones en lenguas extranjeras, 1976, 359.

17 Entrevista realizada por Álvaro Acevedo Tarazona a Armando Martínez Garnica el 26 de octubre de 1999. 
literaria y ensayística de R.H. Moreno Durán quien no duda en caracterizar como religioso y autoritario los valores e ideologías de aquella generación universitaria de izquierda ${ }^{18}$.

La defensa a ultranza de la lucha armada y del abstencionismo eran la otra cara del desprecio por la democracia "burguesa occidental". Políticamente reivindicaban la dictadura del proletariado como la mejor forma de garantizar los medios que prometía el sistema democrático. Al hablar de la revolución de Nueva Democracia los maoístas se referían a una democracia en sentido socioeconómico, es decir, un sistema de organización que garantizara la satisfacción de las necesidades básicas, así no se reparara en las libertades ciudadanas. La Nueva Democracia implicaba una fase de transición que bajo el gobierno del proletariado completaría las tareas burguesas pendientes. En otras palabras, se pensaba en una democracia para el pueblo y una dictadura para los reaccionarios. En Colombia el uso de la democracia liberal fue más instrumental, pues la libertad era considerada un medio para el objetivo final de la dictadura proletaria socialista. De ahí que las luchas por las reformas se asumían como un paso menor, e incluso en un obstáculo para alcanzar el objetivo revolucionario.

Si el desprecio por la democracia "burguesa" fue el corolario para aislarse de la sociedad que pretendían cambiar, en el nivel interno de la militancia las formas democráticas también fueron desplazadas por las enseñanzas bolcheviques, particularmente el famoso centralismo democrático. La discusión y el disenso o la toma de decisiones desde la base se vieron anuladas por el estalinismo que asumió la mayoría de organizaciones clandestinas. Cualquier conato de inconformidad o cuestionamiento respecto al dogma era tratado como una acción contrarrevolucionaria que necesitaba ser extirpada. Incluso en el MOIR, en el que el militarismo no era dominante, las soluciones antidemocráticas no se dieron como era de esperarse. La invocación a la libertad tenía el sentido de la liberación nacional del yugo del imperialismo yanqui y sus oligarquías nacionales. Las libertades civiles y políticas eran consideradas una talanquera para la revolución, mientras

18 Luz Mary Giraldo, Diez años sin Moreno-Durán, El Espectador (22 de noviembre de 2015): 38-40. 
que se recurría a un uso instrumental del derecho cuando los militantes se encontraban detenidos o incursos en procesos penales.

El dogmatismo y el radicalismo de los maoístas adquirieron su verdadero contenido en la sujeción de su comportamiento de acuerdo a ciertos cánones del purismo ideológico. Al igual que el credo católico, la vida buena estaría no en esta vida, en el presente, sino en el futuro socialista. La utopía maoísta tenía como escenario principal el campo y como sujeto protagónico al campesinado, así verbalmente hablara del proletariado ${ }^{19}$. El pueblo que se defendía era el campesinado, razón por la que se generó un cierto rechazo a lo urbano. Como parte de ese desprecio a la ciudad y la modernidad occidental, el maoísmo mantuvo una sospecha por los intelectuales y la intelectualidad y, en general, por el pensamiento sin bases reales de aplicación. Emuladores de los principios de la Revolución Cultural China, el maoísmo colombiano fue poco teórico, tal y como lo demuestran sus metodologías pedagógicas para enseñar las tesis fundamentales del pensamiento de Mao. El recurso a la "numerología", para recordar los aportes más importantes de Mao al pensamiento revolucionario, fue efectivo para transformar mentes que no requiriesen del pensamiento teórico.

Aunque el campesinado fue casi deificado, en el fondo las vanguardias de la nueva izquierda maoísta mantuvieron una perspectiva paternalista, pues el pueblo solo no era capaz de hacer la revolución. Los líderes de estos grupos se consideraban así mismos como una élite más o menos ilustrada que tenía como misión orientar al pueblo por el verdadero camino revolucionario. De allí la preocupación por crear el auténtico partido de vanguardia y por la claridad ideológica que exigía toda acción política. Si bien en el campo del marxismo-leninismo se dio una postura refractaria respecto al mundo académico, al punto de obligar a sus militantes universitarios a dejar la universidad para ir al mundo "real". Tal como lo refiere Martínez Garnica, "en ese tiempo nosotros queríamos hacer una universidad revolucionaria y combativa al servicio del pueblo y contra el imperialismo, no

19 Armando Martínez Garnica recuerda que muchos de sus colegionarios adoptaron la costumbre de dormir en el suelo, a lo sumo sobre una estera, como símbolo de su compromiso con el pueblo pobre al que deseaban defender. Entrevista realizada por Álvaro Acevedo Tarazona a Armando Martínez Garnica el 26 de octubre de 1999. 
se hablaba de una universidad académica con programas de calidad, eso no nos importaba..."20. Esto se logró por una orientación ético-política considerable de servicio al pueblo con las campañas de "bolchevización" y de "pies descalzos". La moral que crearon sus militantes implicó un alto sacrificio material y afectivo, especialmente en el sentido del desprendimiento de los lazos "pequeñoburgueses" propios de las relaciones familiares y de pareja. Lya Fernández, por ejemplo, recuerda que algunos de sus compañeros de estudio habían renunciado a todo en nombre de la revolución: "eran capaces de renunciar absolutamente a todo, inclusive a los otros compañeros, no les importaba la familia, para ellos había algo más importante que la familia y era su compromiso con la revolución"21.

La vida privada también debía sujetarse a los principios ideológicos y a los controles que cada organización establecía. El argumento principal para entrometerse en situaciones personales era el de la seguridad de la organización, a pesar de que algunos de los conflictos que se presentaron tenían como causa problemas sentimentales. Lya Fernández, por ejemplo, tuvo que terminar su noviazgo con Leandro Correa, un miembro del ELN, porque pese a que este hiciera lo imposible por mantenerla al margen de su actividad subversiva, el grupo no dudaba en señalarle su falta de compromiso con la revolución. De hecho, Lya tuvo que esconderse durante 10 meses para evitar que tanto la policía como los miembros del ELN la interrogaran sobre las acciones de su pareja ${ }^{22}$. ¿Hay ejemplos de esto? De otra parte, la gran mayoría de los militantes fueron ascéticos en su vida cotidiana. En otros términos, a diferencia de otros grupos de la nueva izquierda, para quienes la vida bohemia era parte de las sociabilidades políticas, los maoístas no consumían licor ni mucho menos sustancias alucinógenas y tampoco rumbeaban; aunque sí fumaban tabaco de manera desaforada, según los testimonios recogidos por Frank Molano ${ }^{23}$. La forma como asumieron algunos de los planteamientos del marxismo, la actitud contra el disenso, muy cercana a la de los católicos contra los herejes, y la realización

20 Entrevista realizada por Álvaro Acevedo Tarazona a Armando Martínez Garnica el 26 de octubre de 1999.

21 Entrevista realizada por Álvaro Acevedo Tarazona a Lya Fernández el 29 de octubre de 1999.

22 Entrevista realizada por Álvaro Acevedo Tarazona a Lya Fernández el 29 de octubre de 1999.

23 Frank Molano, La izquierda maoísta colombiana, 371-373. 
de algunos rituales pseudo-religiosos, como casarse bajo la mirada de un cuadro de Mao, permite decir que el campo ML fue el más religioso de todas las corrientes de la nueva izquierda en el país.

Pese a las posturas antioccidentales de gran parte del maoísmo, la militancia de sus miembros incidió en el desarrollo de algunas expresiones artísticas de acuerdo a las tesis del Foro de Yenán elaboradas por Mao. Entre los escenarios que se pueden destacar estuvo el teatro universitario con personajes como Fausto Cabrera, Paco Barrero, los hermanos Moure y Jairo Aníbal Niño, quien participó en el Teatro de la Universidad Libre. En la música se destacó el grupo Son del Pueblo que contó en una época con Bruno Díaz, mientras que la pintura tuvo como representante a Consuelo Lucena. En el plano gráfico, la izquierda en su conjunto reconoció la innovación de la publicidad política del MOIR, vistosa e impactante.

El maoísmo como corriente de pensamiento y práctica política no tuvo una larga vida en la izquierda colombiana. A excepción del MOIR que todavía participa en elecciones y obtiene escaños en el Congreso de la República, los demás grupos desaparecieron tras el viraje que dio la misma República Popular China con la muerte de Mao a mediados de los años 70. El automarginamiento de la política y la realidad nacional terminó por asfixiar a la militancia que, incluso en su versión armada, resultó desmovilizándose en la década de los 90.A manera de balance, puede decirse que el maoísmo aportó a la izquierda un nuevo aliento revolucionario, congelado de alguna manera por la experiencia soviética. A pesar de su dogmatismo y profundo sectarismo y casi devoción religiosa hacia el "pensamiento Mao Tse Tung” o su rechazo a las reformas, varios grupos ayudaron a ganar reivindicaciones laborales en el mundo sindical y obtener algunas ventajas en el acceso a la tierra, la vivienda y los servicios públicos.

Indirectamente, el maoísmo en el país propició una crítica a las armas y reflexiones sobre la pertinencia sobre el abstencionismo. Por otro lado, sugirió con su antioccidentalismo, una crítica al eurocentrismo, tendencia que sería retomada más adelante por corrientes como el poscolonialismo. Paradójicamente, impulsó en sectores populares cierta secularización, al tiempo que facilitó la impugnación de las pautas patriarcales y machis- 
tas de comportamiento. Finalmente, el campo ML representó, en alguna medida, el paso de una cultura oral, provinciana y conservadora, a una cultura más urbana y de resistencia, así fuese a través de manuales y afín a corrientes de pensamiento como el marxismo. Más allá de los errores políticos y de sus procedimientos para resolver pugnas y tensiones, no se puede desconocer esa ética de servicio y de sacrificio, que, en muchas ocasiones, fue el resultado de un gran coraje y valentía de sus militantes ${ }^{24}$. El maoísmo concentró en su particular trasegar el proceso de revolución cultural en nuestro país, propuso algunos puntos de encuentro con otras formas y expresiones de la nueva izquierda y se conectó con ciertos acontecimientos mundiales.

\section{A Manera de Cierre}

Entre las décadas de los 60 y 70 del siglo XX el país experimentó con toda la fuerza e intensidad la emergencia de una gran cantidad de grupos de izquierda, debido al influjo de las tendencias mundiales que estaban en boga en aquellos años. Acontecimientos como la Revolución Cubana, el conflicto entre los Partidos Comunistas de la Unión Soviética y China, experiencias políticas como la albanesa o la chilena y corrientes de renovación de la Iglesia Católica afectaron e incidieron de manera directa en la eclosión de lo que se ha dado en llamar Nueva Izquierda. Esta realidad permite sostener que nuestro país no era ajeno para los años 60 y 70 a la influencia de hechos y procesos históricos globales tanto a nivel político como cultural.

Una de las características más importantes de esta miríada de grupos y organizaciones, que, a su turno fue un punto de encuentro, tiene que ver con la crítica sistemática a la izquierda "tradicional" representada en el

24 Mauricio Archila, El maoísmo en Colombia, 193-213. Por su parte, Frank Molano refiere varios aspectos enunciados por Archila, específicamente, en lo relacionado con la mentalidad anticapitalista y antimoderna. Es así como afirma que los miembros de la Liga ML tenían prohibido ver televisión "burguesa", escuchar cadenas radiales "burguesas e imperialistas" así como leer prensa procapitalista. Sus fuentes de información únicamente podían ser aquellas que provenían de la República Popular China: Radio Pekín, Radio Tirana, el periódico de la Liga Nueva Democracia o las revistas, literatura o cine chino. Frank Molano, La izquierda maoísta colombiana, 364. 
Partido Comunista Colombiano. Tildados de "mamertos" 25 , revisionistas y entreguistas, los miembros del PC fueron objeto de críticas por parte de los nuevos grupos, por el hecho de asumir como propias las directrices emanadas desde el Kremlin. La construcción del socialismo en un solo país desde los años de Stalin vino a complementarse con la tesis de la coexistencia entre el capitalismo y el socialismo. A ello se sumó la idea de una transición "pacífica" al socialismo, tal y como se estaba viviendo en el Chile de Salvador Allende.

Además de la pugna con los comunistas, la Nueva Izquierda logró construir, tácitamente, una serie de puntos de encuentro que la caracterizaron respecto a la izquierda "tradicional". El primero de ellos fue el respaldo abierto a la lucha armada como la forma más alta de lucha política. El rescate de experiencias exitosas como la rusa, la china, la cubana, además de la resistencia vietnamita y las luchas de liberación nacional, posicionaron la toma de las armas como un símbolo de auténtico compromiso revolucionario. La tradición colombiana de las guerras civiles y la organización de guerrillas vino a complementar la deificación de la lucha armada, opción que encantó a una generación de universitarios, quienes deseosos de emular al Che, Fidel, Mao Tse-Tung o Ho Chi Minh se unieron a grupos de jóvenes revolucionarios.

La vida militante en periodos de agitación, campaña electoral o de latencia originó todo un estilo de vida en la izquierda colombiana. Muestra de ello fue la definición de un atuendo arquetípico, que en el caso de los maoístas consistió en gafas redondas estilo Trotsky, bufanda, botas de gamuza y

25 De acuerdo con Ricardo Sánchez, el significado de la palabra mamerto para esta época, tenía que ver con el cansancio y abandono de los miembros del PC de la causa revolucionaria:" [...] esta expresión de mamerto quiero aclarar tiene un profundo contenido popular, es decir, es algo que surge de la crítica de sectores populares y consiste sencillamente en la expresión común entre nosotros de habérsele "mamado" a la lucha revolucionaria". Ver Umberto Valverde, Colombia: tres vías a la revolución (Bogotá: Círculo Rojo Editores, 1973), 166. En un reciente artículo publicado en la revista El Malpensante, Julia Londoño sugiere que si bien el significado del término mamerto no se ha establecido con claridad, este pudo haberse derivado de un juego de palabras consistente en que varios de los fundadores del PC tenían nombres que terminaban en "erto": Gilberto, Roberto, Alberto. Por extensión, a los militantes del partido se les llamaba mamertos. Ver: Julia Londoño, "La diva de la JUCO: testimonio de Amalia Lú Posso”, El Malpensante, No. 126 (2011): 39. 
chaqueta $^{26}$. De acuerdo al lugar ocupado en la estructura, el material de la chaqueta cambiaba: de cuero para la dirigencia y de gamuza para las bases. Los socialistas por su concentración en la Universidad del Valle y, en general, en el Valle del Cauca ganaron la fama de ser muy rumberos y bohemios, pues al lado de la disciplina y el compromiso militante propiciaron espacios de sociabilidad en torno a la salsa, el canto y el trago, prácticas que también se daban en otros grupos de la nueva izquierda como la $\mathrm{JUCO}^{27}$. Como parte del activismo más vital y menos monástico, los socialistas se interesaron por formarse artísticamente sin desconocer la relación entre cultura y política reflexionada por Trotsky. Muestra de ello fue la creación de grupos artísticos como la Brigada Socialista de la Canción y el Grupo Teatral La Carpa ${ }^{28}$.

\section{Bibliografía}

Acevedo Tarazona, Álvaro. La experiencia histórica del cogobierno en la Universidad Industrial de Santander: Concepciones y divergencias en disputa por la autonomía universitaria, 1971-1976. Bucaramanga: Universidad Industrial de Santander, 2015, 230.

Acevedo Tarazona, Álvaro. Entrevista a Armando Martínez Garnica, 26 de octubre de 1999.

Acevedo Tarazona, Álvaro. Entrevista a Lya Fernández, 29 de octubre de 1999.

Acevedo Tarazona, Álvaro. Entrevista a Rodolfo Posada, 15 de noviembre de 2008.

26 Rodolfo Posada recuerda que "Sí, andaban, bueno, todo mundo usaba gorra... Sí, pero los maoístas, los maoístas una gorra. Ah, la famosa gorra, las botas de gamuza, la chaqueta y la bufanda. Y algunos adicionaban las gafas, sí, y los trotskistas con una mochila cruzada, eran como los símbolos de su adhesión a la causa." Entrevista realizada por Álvaro Acevedo Tarazona a Rodolfo Posada el 15 de noviembre de 2008 .

27 Para una aproximación al mundo de la cotidianidad universitaria en Colombia, a propósito de las diferentes agrupaciones de izquierda, véase: Acevedo Tarazona, Álvaro. La experiencia histórica del cogobierno en la Universidad Industrial de Santander: Concepciones y divergencias en disputa por la autonomía universitaria, 1971-1976. Bucaramanga: Universidad Industrial de Santander, 2015, 230

28 Martha Cecilia García Velandia, "El presente es de lucha: el futuro socialista”, en Una historia inconclusa: izquierdas políticas y sociales en Colombia, Mauricio Archila (Bogotá: CINEP/COLCIENCIAS, 2009), 141-178. 
Archila, Mauricio. Una historia inconclusa: izquierdas políticas y sociales en Colombia. Bogotá: CINEP/COLCIENCIAS, 2009.

Archila, Mauricio. "El maoísmo en Colombia: la enfermedad juvenil del marxismo-leninismo". En: Una historia inconclusa: izquierdas políticas y sociales en Colombia, editado por Mauricio Archila. Bogotá:CINEP/COLCIENCIAS, 2009, 179-183.

Cadena Castro, Laura. Entrevista a Aura María Puyana Mutis, 23 de febrero de 2010.

¿De dónde venimos, hacia dónde vamos, hacia dónde debemos ir? Medellín: Editorial 8 de junio, 1975.

Díaz Jaramillo, José Abelardo. "Del liberalismo al maoísmo: encuentros y desencuentros políticos en Francisco Mosquera Sánchez, 19581969”. Anuario Colombiano de Historia Social y de la Cultura, Vol. 38 No. 1 (2011): 141-176.

García Velandia, Martha Cecilia. "El presente es de lucha: el futuro socialista”. En: Una historia inconclusa: izquierdas políticas y sociales en Colombia, editado por Mauricio Archila. Bogotá: CINEP/COLCIENCIAS, 2009, 141-178.

Giraldo, Luz Mary. Diez años sin Moreno-Durán. El Espectador (22 de noviembre de 2015): 38-40.

González Bernaldo, Pilar. "La sociabilidad y la historia política". En: Nuevo Mundo Mundos Nuevos [En línea], Puesto en línea el 17 febrero 2008. BAC - Biblioteca de Autores del Centro, http:// nuevomundo. revues.org/24082

Loaiza Cano, Gilberto. Sociabilidad, religión y política en la definición de la nación colombiana, 1820-1886, Bogotá: Universidad Externado de Colombia, 2011.

Londoño, Julia. "La diva de la JUCO: testimonio de Amalia Lú Posso". El Malpensante, No. 126 (2011).

López de la Roche, Fabio. Izquierdas y cultura política: ¿’oposición alternativa? Bogotá: CINEP, 1994.

Medina Gallego, Carlos. FARC-EP: temas y problemas nacionales. 19582008. Bogotá: Universidad Nacional de Colombia, s.f.

Medina Gallego, Carlos. "FARC-EP: notas para una historia política, 1958-2006”. Tesis Doctorado en Historia, Universidad Nacional de Colombia, s.f. 
Medina Gallego, Carlos. "ELN-Ejército de Liberación Nacional: notas para una historia de las ideas políticas: 1958-2007”. Tesis Doctorado en Historia, Universidad Nacional de Colombia, s.f.

Molano, Frank. "La izquierda maoísta colombiana: organizaciones y mentalidades en la década de 1970”. En Para reescribir el siglo XX: memoria, insurgencia, paramilitarismo y narcotráfico, editado por Olga Yanet Acuña Rodríguez y Javier Guerrero Barón. Medellín: La Carreta/UPTC, 2011.

Molina, Gerardo. Las ideas socialistas en Colombia. Bogotá: Tercer Mundo, 1987.

Pizarro León-Gómez, Eduardo. Las FARC 1949-2011: de guerrilla campesina a máquina de guerra. Bogotá: Norma, 2011.

Restrepo, Luis Alberto. El potencial democrático de los movimientos sociales y de la sociedad civil en Colombia. Bogotá: Corporación Viva la Ciudadanía, 1993.

Short, Philip. Mao. Barcelona: Crítica, 2011.

Tse-Tung, Mao. "Sobre la nueva democracia". En Obras Escogidas de Mao Tse-tung, Pekín Tomo II, Ediciones en lenguas extranjeras, 1976, 353-400.

Valverde, Umberto. Colombia: tres vías a la revolución. Bogotá: Círculo Rojo Editores, 1973.

Villarraga, Álvaro y Nelson Plazas. Para reconstruir los sueños: una historia del EPL. Bogotá: Fundación Progresar, 1994.

Para citar este artículo: Acevedo Tarazona, Álvaro. "Ideología revolucionaría y sociabilidad política en los grupos universitarios maoístas de los años 60 y 70 en Colombia", Historia Caribe Vol. XI No. 28 (Enero-Junio 2016): 149-175. DOI: http://dx.doi.org/10.15648/hc.28.2016.6 